\title{
29
}

\section{Compare Your Performance and Practice with the World Excellence: A Prototype of a Benchmarking System}

\author{
Jens O Riis ${ }^{1}$, Frank Gertsen ${ }^{1}$ and Hongyi Sun ${ }^{2}$
}

1 Dept of Production, University of Aalborg, Fibigerstraede 16, 9220 Aalborg, Denmark

2 Dept of Business Administration, Stavanger University Centre, PoB 2557 Ullandhaug, 4004 Stavanger, Norway

To find a partner company is a critical element of benchmarking, partly because it requires the establishment of a win-win situation, partly because of the magnitude of resources and effort needed. In this paper we propose to use the results of an international survey as a basis for reference points and to use the questionnaire as an instrument for assessing the company's goals, performance and practice. A benchmarking system is proposed which indicate relevant factors to benchmark. The way in which reference points are established is demonstrated by means of examples.

\section{INTRODUCTION}

A recent survey has revealed that $50 \%$ of the 600 sample companies from 20 countries claimed to have used benchmarking "). This signals the relevance of benchmarking and a significant interest in working with this method. However, as benchmarking as a management method emerges, it is essential to clarify its role and to address practical issues of benefit versus the effort used.

We see the significance of benchmarking as providing a reference for an enterprise as a vehicle for generating momentum within the company to improve its performance.

In carrying out benchmarking the selection of a partner company has proven to be critical. Although the benefits of comparing both performance and practice with a well renowned enterprise is without doubt, the mere acceptance of the company partner and willingness to serve as a partner is often difficult, e.g. because of fear of disclosing sensitive data. Often, the only chance is to create a "win-win" situation

*) International Manufacturing Strategy Survey (IMSS). We would like to thank Dr Per lindberg at Chalmers University and Professor Chris Voss at London Business School for the initiation of the IMSS project. We also give gratitude to Danish Technical Research Council (STVF) for its partial financial support of this research through Integrated Production Systems (IPS) project. 
which requires that the initiating company itself may offer a significant contribution in the benchmarking process. In addition, the effort needed is considerable.

In shaping the content of the theory and practice of benchmarking it appears relevant to seek alternative ways than bi-lateral benchmarking. As an outcome of participating in an international survey on manufacturing, we have developed a method for displaying the individual respondent in comparison to the best in the population, the median company, and the weakest. In this paper we shall first introduce the survey and use it for proposing a benchmarking system of factors to incorporate in benchmarking. Then examples will be presented to demonstrate the way in which an individual enterprise may compare one factor. At the end of the paper we shall discuss the merit and limitations of the approach.

\section{A PROTOTYPE OF A BENCHMARKING SYSTEM}

In 1993, an international survey was conducted covering 600 industrial enterprises from 20 countries (Argentina, Australia, Austria, Belgium, Brazil, Canada, Chile, Denmark, Finland, Germany, UK, Italy, Japan, Mexico, Netherlands, Norway, Portugal, Spain, Sweden and USA 1). Most of the companies are producers of electrical and metal products. The size distribution of the IMSS survey is shown in table 1.

Table 1 Size distribution of participating enterprises in the IMSS survey

\begin{tabular}{|c|c|c|}
\hline Size & $\mathbf{N}$ & $\%$ \\
\hline$<50$ & 18 & $3 \%$ \\
\hline $51-500$ & 332 & $55 \%$ \\
\hline $501-1000$ & 130 & $22 \%$ \\
\hline $1001-5000$ & 91 & 15 \\
\hline$>5000$ & 14 & $2 \%$ \\
\hline
\end{tabular}

The IMSS survey studies three categories of factors: goals, performance, and practice. Goals include management statement of goal priority (e.g. quality, cost, delivery, etc.) and the extent to which manufacturing strategy is linked to corporate strategy. Performance factors are concerned with business performance, such as return on investment, inventory turnover, etc., and manufacturing performance, such as cost, quality and delivery. Practice is divided into three groups of factors: technology, organization and programs.

In general, it is a complex matter to define relevant factors to benchmark. Having worked with the questionnaire during interviews of top executive, we have observed that the factors dealt with are considered relevant. Furthermore, it is possible with an effort of two to three hours to fill in the questionnaire. For this reason, we shall pro- 
pose a benchmarking system with a list of relevant factors covering goals, performance and practice be adopted from that of the IMSS survey. It is shown in table 2.

Table 2 Factors in the proposed benchmarking system

\begin{tabular}{|c|c|c|}
\hline $\begin{array}{l}\text { GOALS \& } \\
\text { STRATEGY }\end{array}$ & $\begin{array}{l}\text { Company goals } \\
\text { Market feature } \\
\text { Mfg. Strategy }\end{array}$ & $\begin{array}{l}\text { Priority in quality, cost delivery service etc. } \\
\text { Market coverage, focus and development } \\
\text { Linkage of manufacturing strategy and goals }\end{array}$ \\
\hline \multirow[t]{2}{*}{ PERFORMANCE } & $\begin{array}{l}\text { Business } \\
\text { performance }\end{array}$ & $\begin{array}{l}\text { Return on investment } \\
\text { Sales on Investment } \\
\text { Return on sales } \\
\text { Profit per person } \\
\text { Sales per person } \\
\text { Market share }\end{array}$ \\
\hline & $\begin{array}{l}\text { Manufacturing } \\
\text { performance }\end{array}$ & $\begin{array}{l}\text { Quality } \\
\text { Manufacturing cost } \\
\text { Unit cost improvements } \\
\text { Cost structure } \\
\text { On-time delivery } \\
\text { Procurement lead-time } \\
\text { Design lead-time } \\
\text { Manufacturing lead-time } \\
\text { Distribution lead-time }\end{array}$ \\
\hline \multirow[t]{3}{*}{ PRACTICE } & Organisation & $\begin{array}{l}\text { Human aspects } \\
\quad \text { Education, suggestions, teams, etc. } \\
\text { Integration aspects } \\
\quad \text { Co-ordination between department } \\
\text { Structure } \\
\quad \text { Level, span }\end{array}$ \\
\hline & Technology & $\begin{array}{l}\text { Production technology } \\
\text { NC, FMS, Robots, CIM etc. } \\
\text { Engineering technology } \\
\text { CAD, CAD/CAM, CIM } \\
\text { Management technology } \\
\text { MIS, network, CIM }\end{array}$ \\
\hline & Programmes & $\begin{array}{l}\text { Quality } \\
\text { Total quality control, zero defects, ISO } \\
\text { Production plan } \\
\text { Just in time, MRP } \\
\text { Design } \\
\text { Concurrent engineering, design for } \\
\text { manufacturing/assembly etc. }\end{array}$ \\
\hline
\end{tabular}




\section{EXAMPLES OF BENCHMARKS}

As Danish participants of the IMSS survey, we have used the benchmarking system to analyse Danish data and developed a set of benchmarks at the Danish national level (Gertsen, Sun \& Riis, 1993). The next step is to extend our work to the international level and implement international benchmarks in two or three case companies.

For the sake of comparability, 180 metal-product (International Standard Industry Classification, ISIC 381) companies were selected of the IMSS database. We have chosen to show three different examples of benchmarks, which may be used for benchmarking by all companies in the metal product industry. They illustrate the potential outcome of a cross-sectional comparison. The only effort needed is the time to fill in the IMSS questionnaire. The first benchmark relates to performance, the second to practice, whereas the third to goal priority.

\subsection{Detailed benchmark of return on sales}

Statistically, benchmarking is called "position statistics". The position of an individual company may be expressed in relation to the $25 \%$ fractile and the $75 \%$ fractile, forming three groups of companies: the top $25 \%$, the middle $50 \%$, and the bottom $25 \%$. The scale varies due to purpose and variable. Benchmarks can take on several forms such as column chart, table, line etc.

Figure 1 shows a detailed benchmarking for return of sales (ROS, $n=69)$. This reveals how much profit a company is able to get from each unit of sales. According to the survey, on the average, a company achieves $5 \%$ from sales. The position of a company in this benchmark will tell how good the company is in terms of ROS compared to other companies of the industry.

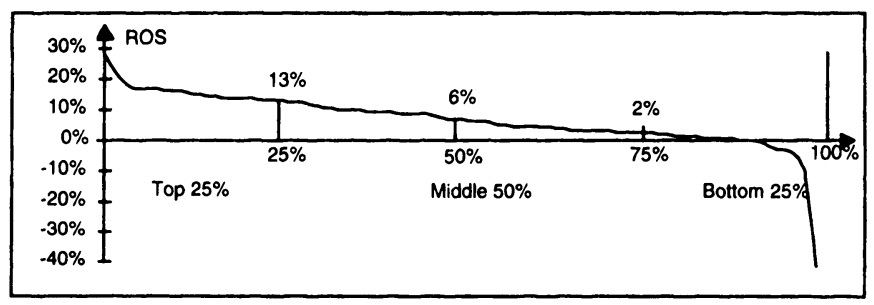

Figure 1 Benchmark of Return on Sales (ROS) in the metal product industry

Another way of displaying the data is shown in figure 2 where the score of the Danish sample companies is displayed on the left side and the percentiles of the international data is shown to the right. 


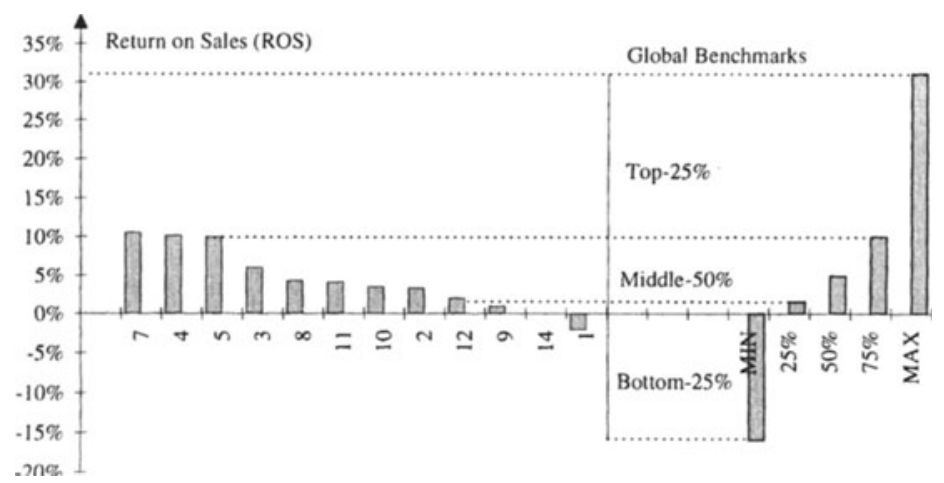

Figure 2 The Danish sample benchmarked on Return on Sales (ROS)

The average ROS of the Top- $25 \%$ is able to achieve US $\$ 31$ from US $\$ 100$ of sales. Most of the Danish sample companies are in the middle $50 \%$ group.

\subsection{Simple benchmark for team utilisation}

A benchmark can also be a simple table with a five point scale. For example, the tables below show two types of benchmarks for team utilisation. Table 3-1 is a percentile benchmark measured by percentage of employees working in teams, while table 3-2 is a 1-5 scale benchmark measured by percentage of companies. We propose that more teams leads to better performance. A company can easily find the figure of its own, and its position in the table, as an indication of its utilisation of teams compared with others.

Table 3-1 Benchmarks by percentile $(n=152)$

\begin{tabular}{|l|l|l|l|l|l|}
\hline $\begin{array}{l}\text { Benchmark } \\
\text { (\% of sample) }\end{array}$ & Min & $\begin{array}{l}\text { Top } \\
75 \%\end{array}$ & $\begin{array}{l}\text { Top } \\
50 \%\end{array}$ & $\begin{array}{l}\text { Top } \\
25 \%\end{array}$ & Max \\
\hline$\%$ of employees & $=0 \%$ & $235 \%$ & $220 \%$ & $250 \%$ & $100 \%$ \\
\hline
\end{tabular}

Table 3-2 Benchmarks by 1-5 scale

\begin{tabular}{|l|l|l|l|l|l|}
\hline $\begin{array}{l}\text { Benchmark } \\
(1-5 \text { Scale })\end{array}$ & None & Little & Some & Much & $\begin{array}{l}\text { A } \\
\text { lot }\end{array}$ \\
\hline $\begin{array}{l}\% \text { of } \\
\text { companies }\end{array}$ & $12 \%$ & $16 \%$ & $27 \%$ & $29 \%$ & $16 \%$ \\
\hline
\end{tabular}

\subsection{Benchmark for company goals priority}

One type of benchmarks aims to show tendency. For example, figure 3 is a benchmark of the priority of different goals of the metal product industry in 19921993 (On the scale a "1" indicates Not Very Important and a "5" Very Important). Similar benchmarks may be made for future goals and market tendency etc. If a 
company makes the same chart of its own and compares it with the benchmark, it may obtains a basis for deciding its business goals.

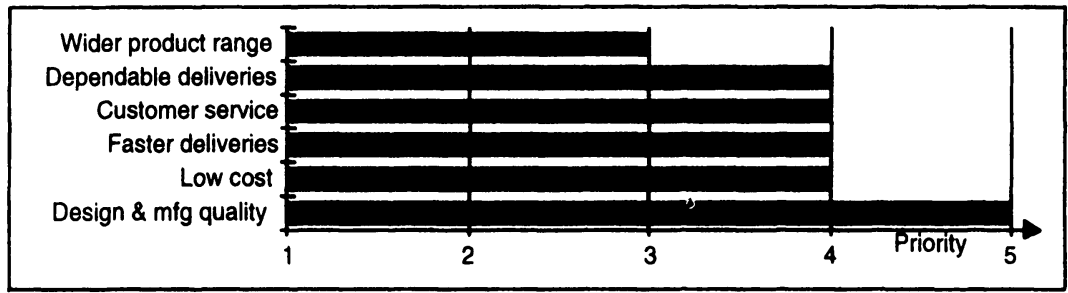

Figure 3 Benchmark for goal priority in the metal product industry 1992-93

\section{DISCUSSION}

The above mentioned examples of benchmarks for goals, performance and practice of industrial enterprises enable a company to position itself in relation to companies in the same country or internationally. In addition, the survey has also been subjected to nation-wise analyses.

One of the advantages of this approach to benchmarking is that an industrial enterprise within the time and effort it takes to fill in a questionnaire may get access to comparisons with other companies on a broad variety of factors covering goals, performance and practice. The benefit of benchmarking, in our view, should be measured in terms of the surprise (shock) and constructive energy it creates within the company. One of the limitations lies in its lack of details and the difficulty of obtaining a more holistic picture of one or more companies attractive for comparison.

The approach to benchmarking may be used as a first screening of factors relevant for further analysis. Experience shows that it is not easy to define relevant indicators or to develop appropriate measurement tools.

Benchmarking as a management method still has to find its place in relationship to Continuous Improvement, Total Quality Management, Total Productive Maintenance, etc. which may call for a distinct, more narrow role of benchmarking as that of providing a reference which may inspire management and employees in a company and generate time, energy and will-power for improvement. On the other hand, we need to develop and test tools for benchmarking that take into account the practical constraints imposed on enterprises. It is our hope that the approach to benchmarking related to an international survey may stimulate this discussion.

\section{REFERENCE}

Gertsen, F., H. Sun and J. O. Riis (1993) Compare your company with the best: a preliminary report of IMSS, University of Aalborg, ISBN: 87-89867-34-3. 